\title{
SAFETY INDEX OF HEAT WAVE MORTALITY USING BIG DATA
}

\author{
J.H. CHUNG, D.W. KIM, J.S. LEE \& S.J. PARK \\ Safety Division, National Disaster Management Research Institute, South Korea.
}

\begin{abstract}
Safety-related research using big data is still in its early stage in Korea. Recently, we have tried to solve some safety-related problems using big data. In this research, we will attempt to solve heat wave-related death which is a significant potential concern associated with climate change.

Although deaths from heat disorders are a direct effect of heat wave incidences, only a few studies have addressed the causal factors between heat wave incidences and deaths from heat disorder. Regression analysis is applied to deduce the causal factors that affect the number of deaths from heat disorders (NDHD) in South Korea by using time-series dataset, which are the NDHD and climate data. Both are observational data from 1994 to 2012, collected from the National Statistical Office and the Korean Meteorological Agency, respectively. As a result, the duration of a heat wave and the age of the population are highly correlated with the NDHD. Based on this correlation, we also analyze the safety index of heat wave mortality.

The paper is structured as follows: First of all, it presents the data and methods, including our strategy for analysis of heat wave incidences based on observational and climate modeling datasets. The next section presents the results of regression models applied for predicting heat wave deaths in Korea and discusses the statistical analysis of the results.
\end{abstract}

Keywords: heat disorders, heat wave, heat wave-related big data, mortality, safety index.

\section{INTRODUCTION}

As the climate change progresses, heat waves become a much greater concern. Recently, the frequency and duration of heat waves have been increasing in most parts of Europe, Asia, and Australia [1-3]. Particularly in Asia, the mortality risk associated with heat waves is predicted to rise continuously even under considerable effort to reduce greenhouse gasses [4]. Heat waves occur almost annually in Korea because of the expansion of the North Pacific High pressure associated with the East Asian summer monsoon system. The Korean Meteorological Agency (KMA) issues a heat wave warning when the daily maximum temperature exceeds the $33^{\circ} \mathrm{C}$ threshold. Heat waves persist for approximately 10 days in mid-summer (July to August) with on average, 21 human deaths by exposure to excessive natural heat. During the anomalous hot summer in 1994, a total of 30 days of heat wave incidences contributed to 93 deaths in Korea. Considering that the annual loss of life from various forms of natural disasters such as typhoons, floods, and heavy snowfalls from 2003 to 2012 averaged to 40 people, the death toll from heat waves is still considered significant especially from a disaster management perspective.

In general, two different forms of statistics may be used to analyze heat-related deaths: the number of excess deaths and the number of deaths from heat disorders (NDHD). The number of excess deaths is calculated by comparing the number of observed deaths with the baseline for a specific period. This number considers the deaths of total population to include not only direct damage of

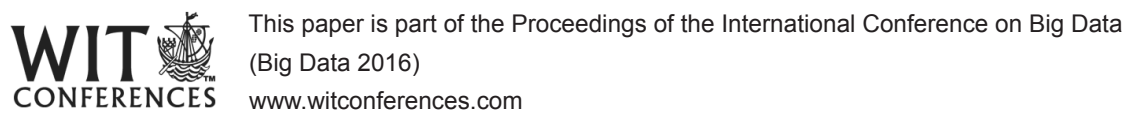

(C) 2016 WIT Press, www.witpress.com ISSN: 1755-7437 (paper format), ISSN: $1755-7445$ (online), http://www.witpress.com/journals DOI: 10.2495/DNE-V11-N3-352-361 
heat wave such as deaths from heat disorders, but also indirect damage such as deaths caused by drowning accidents [5], quality deterioration [6], mortality displacement effect [7] and so on. On the other hand, the NDHD represents only the direct damage caused by an exposure to excessive natural heat (e.g. heatstroke or sunstroke). There also appears to be some ambiguity in regards to whether the deaths during very warm periods are due to heat waves or other causes. For example in Spain, although more than 6,000 excess heat deaths were informally reported during the 2003 heat wave, only 59 of them were officially attributed to the direct result of heat waves [8]. In addition, in Korea there were 3,027 excess heat deaths from July 8 to August 9, 1994, but only 83 deaths were directly attributable to heat waves.

Many studies have used the excessive mortality data to estimate the number of deaths during a particular heat wave event. The data shows alarming number of heat-related deaths worldwide. For example, 2,000 heat-related deaths occurred in 1987 in Greece [9], 1,057 deaths in 1994 in the Netherlands [10], 1,388 deaths in 1994 in Osaka, Japan, [11] and 14,802 deaths in 2003 in France [12]. In order to tackle this very significant challenge, studies have analyzed relationships between air temperature and excessive mortality on national and regional scales in Europe [13]; England and Wales [14]; France [15]; Netherlands [10]; Madrid, Spain [16]; and Moscow, Russia [17]. The purpose of these investigations was to deduce ways to ameliorate the effects of heat waves on humans and provide options for mitigation and adaptation.

Although a relatively small number of studies have dealt with the statistics of NDHD, these data are very important for disaster management. Several countries (e.g. Korea, Japan, and USA) monitor the NDHD to assess heat wave damages rather than calculate the number of excess deaths in that period. In addition, the NDHD can be quantitatively compared to the records of other natural disasters (e.g. USA National Weather Service [18]). In Japan, based on data from 1968-2009, it has been found that 182 people die annually due to heat stroke [19]. Interestingly, the investigation of Hoshi and Inaba [20] that analyzed heat waves in Japan found that the NDHD has been increasing due to the effects of recent climate changes and the vulnerable aging society.

In this study we attempt to provide statistical and modeling evidence on future prediction of heat waves in Korea; as such, studies can empower early detection of the disaster and provide opportunities for mitigation and adaptation. Notwithstanding this notion, most projections of heat wave damages have previously been derived from the statistics of excess deaths based on observed data for vulnerable regions. Based on these predictions, a substantial increase in excess deaths has been deduced for the United States [21], Canada [22], Europe [23], United Kingdom [24], Australia [25], and other regions globally. Most of these studies, however, have not considered the aging demographics and related increases in heat vulnerability. The limitation of such studies is expected to underestimate future heat-related mortality [26]

The purpose of this paper is as follows. First, we deduce the statistics of the NDHD and the causal factors, particularly in relation to aging population in Korea using statistical data for the period 1994-2012 acquired from the National Statistical Office. Second, to study the relationships between NDHD and heat wave, statistics such as the mean maximum temperature (MT), the number of heat wave days (NHW), and the maximum duration of heat wave days (DHW) are examined using linear and multiple regression models.

\section{DATA AND METHOD}

Based on statistics provided by the National Statistical Office on the causes of recorded deaths, the parameter representing the NDHD for the mid-summer period was determined from the period 1994 to 2012. This data had encoded values for the underlying cause of deaths according to Korean Classification of Diseases. We defined the cases of heat-related deaths as the deaths denoted with 
'exposure to excessive natural heat'. The annual death toll and the ratio of unknown causes are represented in Fig. 1.

The ratio of unknown causes was $20 \%$ in 1991 when the collation of these statistics had commenced. However, the proportion of death from unknown causes fell gradually over time, and stabilized at a level of about $2 \%$ by 1995 . Although the proportion in the year 1994 was slightly higher than $2 \%$, we included 1994 in our analysis period as the heat waves during this year were very extreme. Furthermore, our analysis concentrated on data from July and August since the highest number of deaths due to heat disorders ( 437 cases) were recorded during this period.

In order to investigate the incidences of heat waves parameters and related deaths in Korea closely, daily records of maximum temperature (DT) were acquired from 45 observational sites distributed evenly within Korea. As a representative measure of the annual heat wave severity, we calculated three different heat wave parameters using the DT. First was the mid-summer mean DT (MT), second was the NHW, and third was the maximum duration (days) of the heat wave period (DHW). We used the acceptable definition of heat waves defined as a particular day when the magnitude of DT was equal to or higher than $33^{\circ} \mathrm{C}$ [27]. The overall heat wave situation was deduced by averaging the heat wave parameters for all 45 stations considered in this study.

\section{REGRESSION MODELS FOR PREDICTION OF HEAT WAVE-RELATED DEATHS}

Figure 2 shows a stacked bar graph of the time-series of annual heat wave severity parameters and the corresponding NDHD calculated in the mid-summer period from 1994 to 2012. The left ordinate shows the NHW (as actual single days and the maximum duration) and the corresponding mean MT while the right ordinate shows the NDHD for the young $(<65$ years of age) and the elderly $(\geq 65$ years of age). Over the 19-year period, the average value of heat wave parameters, MT, NHW, and DHW were approximately $29.5^{\circ} \mathrm{C}, 11.2$ days, and 4.8 days, respectively. In terms of the overall death toll over this period, there were 437 lives lost due to heat waves with an average of 23 people per summer. However, the present data did not identify any specific trend in NDHD and the frequency of heat waves within the period of study.

A noteworthy point is that in the year 1994 there were exceptional cases of heat wave events, which accorded to an average MT» $32.5^{\circ} \mathrm{C}, \mathrm{NHW} » 30.1$ days and DHW $\gg 14.4$ days. Consequently, the heat wave events during this year contributed to a massive loss of human lives with 93 recorded

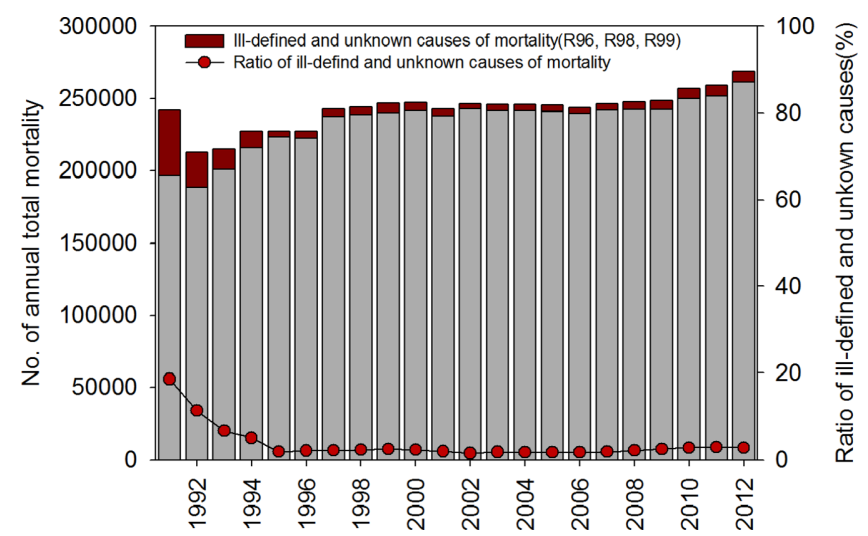

Figure 1: The annual total mortality in Korea for the period 1991-2012. 


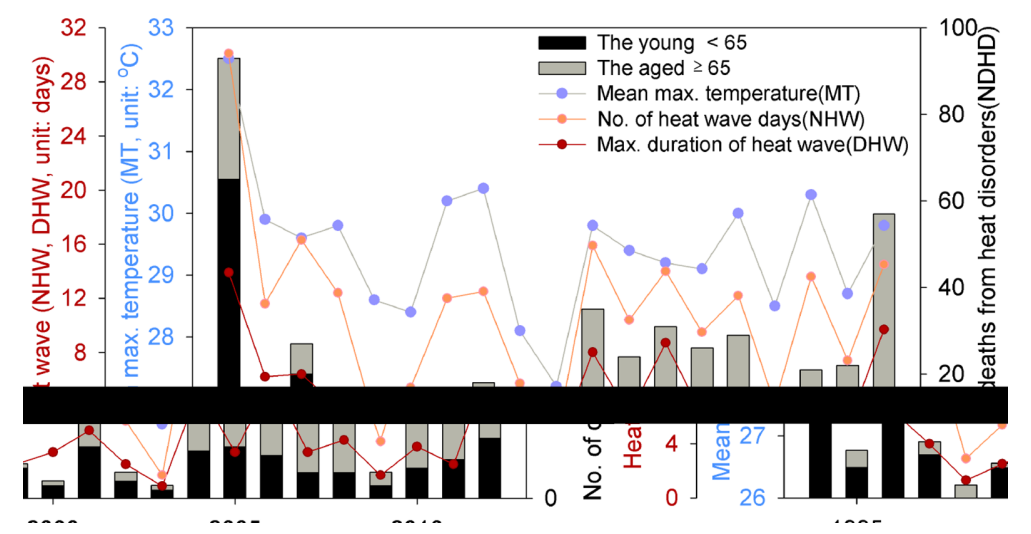

Figure 2: A time-series of the midsummer (July-August) heat wave parameters for the period 1994-2012.

deaths. When the year 1994 was excluded from this time-series dataset, an increasing trend in the magnitude of NDHD was clearly identifiable.

For the purpose of examining closely the decadal changes in magnitude of heat wave parameters, Table 1 displays NDHD, MT, NHW, and DHW for three different time-slice periods (1994-2012, 1995-2003, and 2004-2012). Note that the three time slices were selected carefully to deduce the best possible trends in the magnitude of the heat wave parameters considered in the period of study. Overall, the NDHD were significantly higher in the latter (2004-2012) compared with the earlier (1995-2003) period. Accordingly, the percentage differences in the magnitude of NDHD was approximately $94.4 \%$ higher, the MT was approximately $1 \%$ larger, the NHW was $26.3 \%$ larger, and the DHW was approximately $41.3 \%$ larger in the latter period compared to the former. Importantly, the increase in NDHD was statistically significant at the $99.5 \%$ level of significance.

In terms of the age group analysis, Fig. 2 shows clearly that the significantly large proportion of increases in NDHD was attributable to the elderly population group (aged $\geq 65$ years). When considered by the changes in heat wave severity, the magnitude of MT demonstrated very little variation before and after the year 2004. On the other hand, both the magnitude of the NHW and DHW exhibited distinct increases after the year 2004 by approximately 26.3\% (NHW) and $41.3 \%$ (DHW) although the statistical significance of these increases was relatively low $(\mathrm{p}>0.1)$.

To assess the impacts of heat hazards, a statistical analysis of the relationship between NDHD and heat wave statistics over the period 1994-2012 was performed. To minimize the effects of interannual population changes, the NDHD was normalized per million people in the population. Figure 3 shows a scatterplot of NDHD versus the corresponding predictor values (MT, NHW and DHW). A linear relationship of the form has been identified.

$$
\mathrm{NDHD} » \mathrm{~B} \times \text { predictor }+\mathrm{C}
$$

Note that the heat wave predictors are shown on the abscissa, B is the regression slope and C represents the y-intercept corresponding to 'no deaths' due to heat disorders at the respective values of the predictor.

Despite some obvious scatter, the dependence of NDHD on the MT and NWH appear to be reasonably linear (Fig. 3a and b). We also applied two different statistical measures to examine the behavior of deaths due to heat wave disorder. First, the residuals in linear regression models were 
Table 1: Decadal changes and their statistical significance in terms of the magnitude of NDHD, MT, NHW, and DHW shown in time-slice periods of 1994-2012, 1995-2003 and 2004-2012.

\begin{tabular}{|c|c|c|c|c|c|}
\hline & $\begin{array}{l}1994 \sim \\
2012\end{array}$ & $\begin{array}{l}\text { 1995 } \\
\text { 2003(A) }\end{array}$ & $\begin{array}{l}\text { 2004 } \\
\text { 2012(B) }\end{array}$ & $\begin{array}{l}\mathrm{B}-\mathrm{A} \\
(\mathrm{B} / \mathrm{A}, \%)\end{array}$ & p-value \\
\hline $\begin{array}{l}\text { No. death by heat } \\
\text { disorder(NDHD) }\end{array}$ & 23 & 10.3 & 27.9 & $\begin{array}{c}17.6 \\
(94.4)\end{array}$ & 0.005 \\
\hline $\begin{array}{l}\text { Mean Max. Temp. } \\
\text { (MT) }\end{array}$ & 29.45 & 29.13 & 29.42 & $\begin{array}{c}0.29 \\
(1.0)\end{array}$ & 0.5014 \\
\hline $\begin{array}{l}\text { No. heat wave } \\
\text { days(NHW) }\end{array}$ & 11.17 & 8.94 & 11.30 & $\begin{array}{r}2.36 \\
(26.3)\end{array}$ & 0.2829 \\
\hline DHW & 4.8 & 3.57 & 5.05 & $\begin{array}{r}1.48 \\
(41.3)\end{array}$ & 0.23 \\
\hline
\end{tabular}
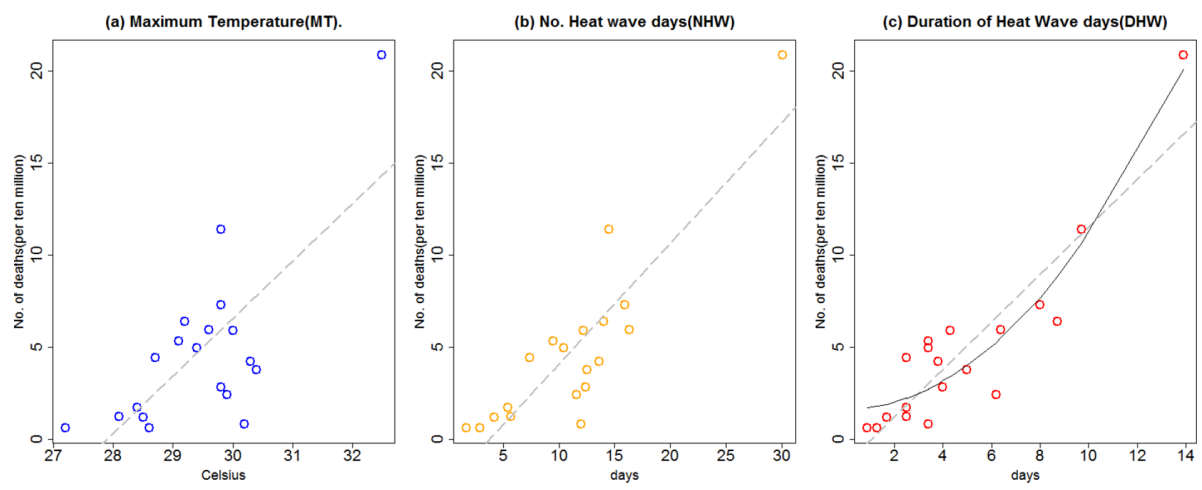

Figure 3: A scatter plots of the number of deaths (NDHD) versus (a) MT, (b) NHW and (c) DHW. In parts a-c, a linear regression line and in part (c), a linear and quadratic regression line is shown.

assessed using the Lilliefors test, which determines the normality based on the Kolmogorov-Smirnov test. Second, the Breusch-Pagan (BP) test examined heteroscedasticity in the regression model. This tested whether the variance of residuals from a regression were dependent on the independent variables. If the p-value for the test is greater than 0.1, the Lilliefors test and BP test are satisfied, respectively.

Table 2 shows the statistical metrics deduced from equation (1). Quite clearly, the linear regression model for NDHD versus MT yielded the lowest R-squared value (»0.54), thus indicating the poor predictability of human deaths caused by MT. On the other hand, the regression model for NDHD versus NHW and DHW performed better in predicting the magnitude of NDHD. That is, the R-squared value was approximately 0.76 (for NHW) and 0.81 (for DHW). Also importantly, the mean square error (MSE) was found to be approximately 2.4 and 2.2 deaths due to heat disorder, respectively, in contrast to approximately 3.3 deaths due to heat disorder, for the MT factor.

The normality and heteroscedasticity of residuals in the regression models examined using the Lilliefors and the BP tests yielded discernible results for the predictability of the NDHD based on 
Table 2: A statistical summary of parameters of a simple linear regression of the form NDHD » B $\times$ predictor $+\mathrm{C}$.

\begin{tabular}{lcccccc}
\hline Predictor & B & $\begin{array}{c}\text { Intercept } \\
(\mathrm{C})\end{array}$ & $\mathrm{R}^{2}$ & MSE & $\begin{array}{c}\text { Lilliefors test } \\
\text { (p-value) }\end{array}$ & $\begin{array}{c}\text { Breusch-Pagan test } \\
\text { (p-value) }\end{array}$ \\
\hline MT** $^{*}$ & 3.111 & -84.749 & 0.54 & 3.3 & 0.69 & 0.01 \\
NHW $^{* *}$ & 0.656 & -2.483 & 0.76 & 2.4 & 0.78 & 0.16 \\
DHW $^{* *}$ & 1.290 & -1.368 & 0.81 & 2.2 & 0.95 & 0.03 \\
DHW $^{2 * *}$ & 0.095 & 1.657 & 0.88 & 1.7 & 0.48 & 0.45 \\
\hline
\end{tabular}

Key: ** Significant at 99\%, * significant at 95\%, MSE: Mean Square Error

MT: mean maximum temperature, NHW: number of heat wave days, DHW: maximum duration of heat wave days

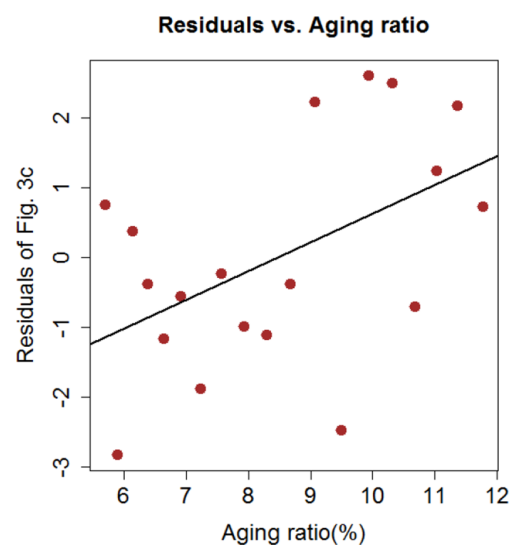

Figure 4: A scatter plot of the residuals of the regression model in Fig. 3c and the Aging Ratio (AR) for the corresponding year.

the various heat wave parameters. Although the DHW model exhibited the highest $\mathrm{R}^{2}$ value, it was unable to satisfy the assumption of heteroscedasticity of the residuals, failing the BP test $(\mathrm{p}<0.05)$. In order to resolve this problem, we transformed the independent DHW variable to its square value, DHW2. As a result, the regression model using $\mathrm{DHW}^{2}$ satisfied the assumption of normality and heteroscedasticity, and improved the predication performance $\left(\mathrm{R}^{2}=0.88, \mathrm{MES}=1.7\right.$ people $)$. We aver that the NDHD is closer to a parabolic rather than a linear dependence on DHW, as noted in previous studies [28].

Figure 4 presents the relationship between the residuals of $\mathrm{DHW}^{2}$ model (Fig. 3c) and the Aging Ratios (AR) for the corresponding year. In general, the residual tends to increase as AR increases. This change was significant at the $90 \%$ level of confidence based on the t-test with satisfying the BP (p-value: 0.713 ) and Lilliefors (p-value: 0.875$)$ tests. As expected, this indicated that both the aging trend and the heat severity factor contributed to an increase in the NDHD. In light of this argument, the $\mathrm{DHW}^{2}$ and $\mathrm{AR}$ are postulated to be the best predictors of the multiple regression model of the form

$$
\mathrm{NDHD}=\mathrm{B}_{1} * \mathrm{DHW}^{2}+\mathrm{B}_{2} * \mathrm{AR}+\mathrm{C}
$$


Table 3: A statistical summary of the parameters of the multiple regression model of the form $\left(\mathrm{NDHD}=\mathrm{B}_{1} * \mathrm{DHW}^{2}+\mathrm{B}_{2} * \mathrm{AR}+\mathrm{C}\right)$.

\begin{tabular}{|c|c|c|c|c|c|c|c|}
\hline & B & $\begin{array}{l}\text { Std. } \\
\text { Error }\end{array}$ & Beta & $\mathrm{R}^{2}$ & MSE & $\begin{array}{l}\text { Lilliefors } \\
\text { Test } \\
\text { (p-value) }\end{array}$ & $\begin{array}{l}\text { Breusch-Pagan } \\
\text { test (p-value) }\end{array}$ \\
\hline Intercept & -1.953 & 1.570 & - & \multirow{3}{*}{0.92} & \multirow{3}{*}{1.4} & \multirow{3}{*}{0.49} & \multirow{3}{*}{0.46} \\
\hline $\mathrm{DHW}^{2}$ & $\begin{array}{l}0.093^{* *} \\
\left(\mathrm{~B}_{1}\right)\end{array}$ & 0.007 & 0.975 & & & & \\
\hline $\mathrm{AR}$ & $\begin{array}{l}0.432 * \\
\left(\mathrm{~B}_{2}\right)\end{array}$ & 0.174 & 0.179 & & & & \\
\hline
\end{tabular}

Key: ** Significant at 99\%, * significant at 95\%, Beta: Standardized Coefficient, MSE: Mean Square Error, DHW: maximum duration of heat wave days, AR: Aging Ratio
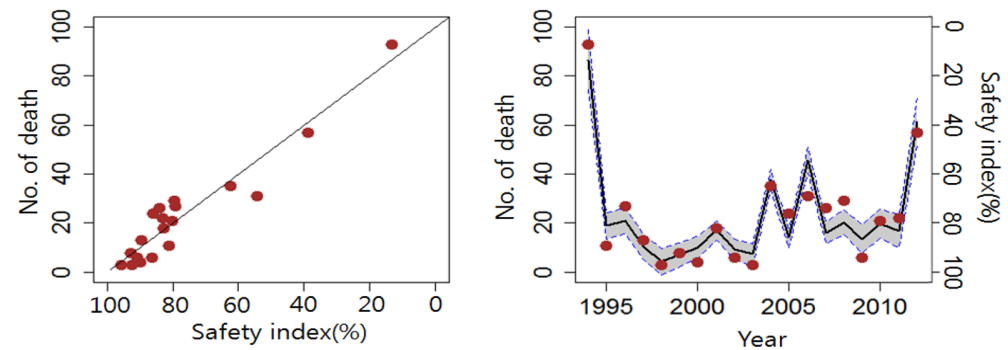

Figure 5: The estimated value of the number of deaths due to heat disorder (NDHD) using the multiple regression model.

Where the constants $\mathrm{B}_{1}$ and $\mathrm{B}_{2}$ are the coefficients of the non-linear and linear components of the regression, respectively, and $\mathrm{C}$ is the $\mathrm{y}$-intercept. Even if we conduct a step-wise regression analysis using SPSS software to deduce the best predictors among the five variables (MT, NHW, DHW, $\mathrm{DHW}^{2}$, and AR), we achieved exactly the same result as in equation (2). It is imperative to mention that the multiple regression model exhibited a significantly large value of $R^{2}(» 0.92)$ and a correspondingly small value of the MSE (»1.4 deaths). Importantly, the regressive relationship between NDHD and $\mathrm{DHW}^{2}$ was statistically significant at the $99 \%$ confidence interval, while that on the AR was statistically significant at the $95 \%$ confidence level. A noteworthy point is that the $\mathrm{R}^{2}$ based on the simple regression model for $\mathrm{DHW}^{2}$ improved from 0.88 to 0.91 and the MSE reduced from 1.7 to 1.4 deaths (Table 2 and 3). Furthermore, in the multiple regression model, the $\mathrm{DHW}^{2}$ exhibited approximately 5.6 times greater effect on the NDHD compared to the effect on the AR, as indicated by the standardized coefficient values $\left(\mathrm{DHW}^{2} \gg 0.975, \mathrm{AR} \gg 0.179\right)$. Overall, the comparison of the estimated and observed deaths using scatter and time-series plots (Fig. 5) showed that the proposed model was able to estimate heat wave-related deaths reasonably well.

\section{DISCUSSION \& CONCLUSION}

In this study we analyzed the NDHD for the Korean region using regression analysis based on observed data (1994-2012). 
(a) 2010 Heat wave

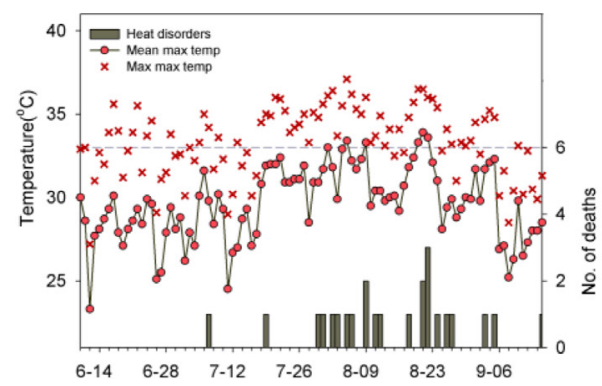

(b) 2012 Heat wave

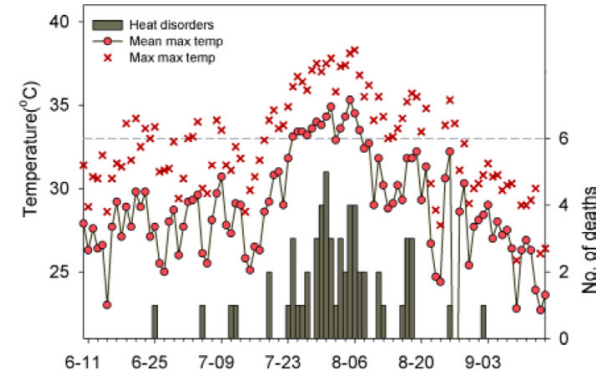

Figure 6: The examples of heat wave events in (a) 2010 and (b) 2012.

Regression analysis was conducted to deduce statistical relationships between the NDHD and the related heat parameters such as the mean MT, the total NHW, the maximum duration (days) of heat wave (DHW), and the aging ratio of population (AR).

Unlike previous studies, we focused on the assessment of direct impact of heat waves on human lives by analyzing the NDHD rather than the indirect impact represented by the excess mortality numbers. The heat wave deaths were defined as the number of deaths caused by exposure to excessive natural heat during the mid-summer period (July to August). A multiple regression model was developed to predict the NDHD, based on a mortality rate of 437 people from 1994 to 2012 (23 people / summer). The best predictors of the regression model were the DHW and the AR. The model formulated using regression analysis was efficient in estimating the NDHD within the period of study.

Although the total NHW is widely considered as a representative variable for heat wave severity, we used the maximum DHW as predictors of human deaths. This followed the notion that as the heat waves progress, not only is more thermal stress accumulated in the human body but also the heat wave extent (such as MT) is intensified. As an example we compared heat wave events that occurred in 2010 and 2012 (Fig. 6). Although the magnitude of MT $\left(30.0^{\circ} \mathrm{C}\right.$ in 2010 and $29.9^{\circ}$ in 2010 ) and the NHW (12.8 days in 2010 and 14.4 days in 2012) were similar, typical heat waves occurred regularly throughout the summer of 2010 while an intense heat wave occurred in late July to early August in 2012. Consequently, 21 people died in 2010 while 57 people died in 2012. This shows that the maximum DHW is of greater concern than the number of heat waves for any given period.

Although the risk of heat wave deaths can be modulated by multiple factors in relation to the ambience, only two environmental elements (DWH and AR) were considered as good predictors of heat waves in this study. The inclusion of other meteorological factors such as humidity as well as social factors such as gender and occupation may also be relevant for the detection of heat wave impacts on people. Therefore, if more detailed mortality statistics are gathered in the future, a wider variety of variables could be considered in order to improve the accuracy of the regression models.

Aging populations are crucial factors that are causing a rise in heat wave risk. For example in Japan, almost 1,718 people died from heat stroke and sunstroke in the year 2010 when serious heat waves lasted for an extended period of time, of which, $79.3 \%$ were elderly people. According to this study, Korea is also expected to experience massive heat wave damage in the near future. Finally, the response to heat waves should be incorporated cautiously in all emergency management plans and contingency measures should be adopted both at the local and national levels. 


\section{REFERENCES}

[1] Stocker, T.F., Qin, D., Plattner, G.K., Tignor, M., Allen, S.K., Boschung, J., Nauels, A., Xia, Y., Bex, V. \& Midgley, P.M., Climate change 2013: The physical science basis. Intergovernmental Panel on Climate Change, Working Group I Contribution to the IPCC Fifth Assessment Report (AR5), Cambridge Univ Press: New York, 2013.

[2] Cowan, T., Purich, A., Perkins, S., Pezza, A., Boschat, G. \& Sadler, K., More frequent, longer, and hotter heat waves for australia in the twenty-first century. Journal of Climate, 27, pp. 5851-5871, 2014. http://dx.doi.org/10.1175/JCLI-D-14-00092.1

[3] Amengual, A., Homar, V., Romero, R., Brooks, H.E., Ramis, C., Gordaliza, M. \& Alonso, S., Projections of heat waves with high impact on human health in Europe. Global and Planetary Change, 19, pp. 71-84, 2014. http://dx.doi.org/10.1016/j.gloplacha.2014.05.006

[4] Field, C.B, Barros, V.R, Mach, K. \& Mastrandrea, M., Climate change 2014: impacts, adaptation, and vulnerability. Contribution of Working Group II to the Fifth Assessment Report of the Intergovernmental Panel on Climate Change, 2014.

[5] Schuman, S.H., Patterns of urban heat-wave deaths and implications for prevention: data from New York and St. Louis during July, 1966. Environmental Research, 5(1), pp. 59-75, 1972. http://dx.doi.org/10.1016/0013-9351(72)90020-5

[6] McMichael, A.J., Anderson, H.R., Brunekree, B. \& Cohen, A.J., Inappropriate use of daily mortality analyses to estimate longer-term mortality effects of air pollution. International Journal of Epidemiology, 27(3), pp. 450-453, 1998. http://dx.doi.org/10.1093/ije/27.3.450

[7] Hajat, S., Armstrong, B.G., Gouveia, N. \& Wilkinson, P., Mortality displacement of heat-related deaths: a comparison of Delhi, Sao Paulo, and London. Epidemiology. 16(5):pp. 613-620, 2005. http://dx.doi.org/10.1097/01.ede.0000164559.41092.2a

[8] Koppe, C., Kovats, S., Jendritzky, G. \& Menne, B., Heat-waves: risks and responses. Health and Global Environmental Change Series No.2, World Health Organization, 2004.

[9] Katsouyanni, K., Trichopoulos, D., Zavitsanos, X. \& Touloumi, G., The 1987 Athens heatwave. The Lancet, 332(8610), p. 575, 1988. http://dx.doi.org/10.1016/S0140-6736(88)92699-2

[10] Huynen, M.M., Martens, P., Schram, D., Weijenberg, M.P. \& Kunst, A.E., The impact of heat waves and cold spells on mortality rates in the Dutch population. Environmental Health Perspectives, 109(5), pp. 463-470, 2001. http://dx.doi.org/10.1289/ehp.01109463

[11] Bai, H., Islam, M.N., Kuroki, H., Honda, K. \& Wakasugi, C., Deaths due to heat waves during the summer of 1994 in Osaka Prefecture, Japan. Nippon Hoigaku Zasshi, 49(4), pp. 265-274, 1995.

[12] Brücker, G., Impact sanitaire de la vague de chaleur d'août 2003: premiers résultats et travaux à mener. Bull, Épidémiol. Hebdomad, 45-46, p. 217, 2003.

[13] Keatinge, W.R., Donaldson, G.C., Cordioli, E., Martinelli, M., Kunst, A.E., Mackenbach, JP., Nayha, S. \& Vuori, I., Heat related mortality in warm and cold regions of Europe: observational study. BMJ, 321(7262), pp. 670-673, 2000. http://dx.doi.org/10.1136/bmj.321.7262.670

[14] Hajat, S., Kovats, R.S., Lachowycz, K., Heat-related and cold-related deaths in England and Wales: who is at risk? Occupational and Environmental Medicine, 64(2), pp. 93-100, 2007. http://dx.doi.org/10.1136/oem.2006.029017 
[15] Laaidi, M., Laaidi, K. \& Besancenot, JP., Temperature-related mortality in France, a comparison between regions with different climates from the perspective of global warming. International Journal of Biometeorology, 51(2), pp. 145-153, 2006. http://dx.doi.org/10.1007/s00484-006-0045-8

[16] Díaz, J., Linares, C. \& Tobías, A., Impact of extreme temperatures on daily mortality in Madrid (Spain) among the 45-64 age-group. International Journal of Biometeorology, 50(6), pp. 342-348, 2006. http://dx.doi.org/10.1007/s00484-006-0033-z

[17] Revich, B. \& Shaposhnikov, D., Temperature-induced excess mortality in Moscow, Russia. International Journal of Biometeorology, 52(5), pp. 367-374, 2008. http://dx.doi.org/10.1007/s00484-007-0131-6

[18] USA National Weather Service Hazard Statistics, available at www.nws.noaa.Gov/om /hazstats.shtml, accessed December 6, 2014.

[19] Japanese ministry of environment (JME), Heat stroke environmental health manual, 2011.

[20] Hoshi, A. \& Inaba, Y., Prediction of heat disorders in Japan. Global Environmental Research, 11, pp. 45-50, 2007.

[21] Jackson, J.E., Yost, M.G., Karr, C., Fitzpatrick, C., Lamb, B.K., Chung, S.H., Chen, J., Avise, J., Rosenblatt, R.A. \& Fenske, R.A., Public health impacts of climate change in Washington State: projected mortality risks due to heat events and air pollution. Climatic Change, 102, pp. $1-28,2010$. http://dx.doi.org/10.1007/s10584-010-9852-3

[22] Cheng, C.S., Campbell, M., Li, Q., Li, G., Auld, H., Day, N., Pengelly, D., Cingrich, S., Klaassen, J., Maclver, D., Comer, N., Mao, Y., Thompson, W. \& Lin, H., Differential and combined impacts of extreme temperatures and air pollution on human mortality in south-central Canada. Part II: future estimates. Air Quality Atmosphere \& Health, 1(4), pp. 223-235, 2009. http://dx.doi.org/10.1007/s11869-009-0026-2

[23] Baccini, M., Kosatsky, T., Analitis, A., Anderson, H.R., D’Ovidio, M., Menne, B., Michelozzi, P. $\&$ Biggeri, A., Impact of heat on mortality in 15 European cities: attributable deaths under different weather scenarios. Journal of Epidemiology and Community Health, 65(1), pp. 64-70, 2011. http://dx.doi.org/10.1136/jech.2008.085639

[24] Doherty, RM., Heal, MR., Wilkinson, P., Pattenden, S., Vieno, M., Armstrong, B., Atkinson, R., Chalabi, Z., Kovats, S., Milojevic, A. \& Stevenson, D.S., Current and future climate-and air pollution-mediated impacts on human health. Environmental Health, 8(suppl 1), p. S8, 2009. http://dx.doi.org/10.1186/1476-069X-8-S1-S8

[25] Guest, C.S., Willson, K., Woodward, A.J., Hennessy, K., Kalkstein, L.S., Skinner, C. \& McMichael, A.J., Climate and mortality in Australia: retrospective study, 1979-1990, and predicted impacts in five major cities in 2030, Climate Research, 13, pp. 1-15, 1999. http://dx.doi.org/10.3354/cr013001

[26] Huang, C., Barnett, A.G., Wang, X., Vaneckova, P., FitzGerald, G. \& Tong, S., Projecting future heat-related mortality under climate change scenarios: a systematic review. Environmental Health Perspectives, 119, pp. 1681-1690, 2011. http://dx.doi.org/10.1289/ehp.1103456

[27] Park, J.G., Jung, W.S., Kim, U.B., Song, J.H. \& Lee, J.U., Study on the extreme heat health watch warning system. National Institute of Meteorological Research, p. 93, 2007. (In Korean with English abstract)

[28] Kim, M.K., Lee, D.H. \& Kim, J., Production and validation of daily grid data with $1 \mathrm{~km}$ resolution in South Korea. Climate Research, 8, pp. 13-25, 2013. (In Korean with English abstract) 